DE DE GRUYTER

OPEN

Polish Cartographical Review

Vol. 48, 2016, no. 1, pp. 17-28

DOI: $10.1515 /$ pcr-2016-0002

TADEUSZ PASTUSIAK

Chair of Navigation, Gdynia Maritime University

tadeusz.pastusiak@wp.pl

\title{
Nautical electronic maps of S-411 standard and their suitability in navigation for assessment of ice cover condition of the Arctic Ocean
}

\begin{abstract}
The research on the ice cover of waterways, rivers, lakes, seas and oceans by satellite remote sensing methods began at the end of the twentieth century. There was a lot of data sources in diverse file formats. It has not yet carried out a comparative assessment of their usefulness. A synthetic indicator of the quality of data sources binding maps resolution, file publication, time delay and the functionality for the user was developed in the research process. It reflects well a usefulness of maps and allows to compare them. Qualitative differences of map content have relatively little impact on the overall assessment of the data sources. Resolution of map is generally acceptable. Actuality has the greatest impact on the map content quality for the current vessel's voyage planning in ice.

The highest quality of all studied sources have the regional maps in GIF format issued by the NWS / NOAA, general maps of the Arctic Ocean in NetCDF format issued by the OSI SAF and the general maps of the Arctic Ocean in GRIB-2 format issued by the NCEP / NOAA. Among them are maps containing information on the quality of presented parameter. The leader among the map containing all three of the basic characteristics of ice cover (ice concentration, ice thickness and ice floe size) are vector maps in GML format. They are the new standard of electronic vector maps for the navigation of ships in ice.

Publishing of ice cover maps in the standard electronic map format S-411 for navigation of vessels in ice adopted by the International Hydrographic Organization is advisable in case is planned to launch commercial navigation on the lagoons, rivers and canals. The wide availability of and exchange of information on the state of ice cover on rivers, lakes, estuaries and bays, which are used exclusively for water sports, ice sports and ice fishing is possible using handheld mobile phones, smartphones and tablets.
\end{abstract}

Keywords: ice cover maps, standard IHO S-411, safety of water transport, Northern Sea Route

\section{Introduction}

At the end of the XX century, the research of ice cover of waterways, rivers, lakes, seas and oceans with satellite remote sensing methods was commenced. The notion "freezing" should be understood the coverage of areas of water (seas, lakes, rivers) by ice. The term "ice cover" should be understood a layer of ice located on surface of the water. Began to appear more and more accurate measuring methods. Systematically increased the number of information sources freely available on the Internet. At the same time it used many forms of data storage. Some of them have limited applicability due to the lack of widely available and easy-to-use utilities and mobile applications. The same time were introduced for use on board ships electronic charts and standardized ECDIS ${ }^{1}$ navigation systems. The first basic software could show the GPS position on chart in the background as another information layer. Subsequent software presented more and more layers of information. In the next place so there were software ECS. Only software that meet the standards of the International Maritime Organization (IHO 2000/1) could be called ECDIS. More information about systems that display nautical charts and information can be read in a book of $A$. Weintrit (2009).

At the beginning the navigational charts RNC, i.e. geo-referenced scanned paper maps

\footnotetext{
${ }^{1}$ List of acronyms is attached at the end of the article.
} 
were used. They are being replaced by electronic vector charts ENC. Standard electronic vector maps of ice cover on the water in Geography Markup Language GML format (IHO JCOMM 2014) was developed just in 2014 for displaying in navigation systems as another information layer. Since the beginning of 2016, there are maps available subsequent regions of the Arctic and Antarctic. Heretofore used GPS, ECS and ECDIS navigation software do not support GML files. Few exceptions are GIS-ish QGIS software available for multiple operating systems for personal computers and Global Mapper software that is able to identify the basic parameters of the position and motion of the vessel from the GPS receiver connected to a computer. Currently, crews must use additional GIS software. Such software, especially when it is able to visualize the position of the ship on the background of the ice cover map takes on the status of supporting software, which complements the officially approved basic charts and navigation systems required by the SOLAS Convention (http://www.admiralty.co.uk/Pages/FAQ-Industry-Facts.aspx and http://www.amsa.gov.au/navigation/resources/ecdis/documents/ecdisuse.pdf, accessed 20.02.2016).

Due to the widespread use of mobile phones, smartphones and tablets, that operate in between under Android operating system, the question arises about the availability of GIS, GPS and ECS software, that allow to visualize ice cover maps by large group of water and ice sports enthusiasts and fishermen fishing under ice. Visualization of ice sheet of commercially used rivers and waterways seems to be particularly useful due to devices commonly used to download maps from the Internet and then visualize onto its navigation supporting software.

On the background of the above, there is the main objective of this work, which is to compare the quality of the information on the maps of ice cover in the new IHO standard (2014) in relation to previously widely available maps in other formats.

\section{Research method}

In the opinion of the author, users of "land" maps (e.g. topography) are accustomed that the accuracy of the position of the object shown on the maps is high ( 20 or more meters and even several centimeters in case of GPS without improving position accuracy when using DGPS or in case of theodolite triangulation) and does not require special considerations. For this reason, has been paid special attention in the work for the problems of low-precision data and a very low position accuracy of a map content generated by satellite remote sensing methods (for example: data sources from different manufacturers and data sources described in different file formats). The notion of position accuracy is widely used in geodesy and his "reversal" is the concept of "dilution of position" HDOP. For the purpose of the present study it was decided to create a "comparable" for geodesy concept of "dilution of position $D$ ".

The research work is based on a qualitative analysis of selected information sources. The maps representing all file formats freely available for public in the Internet were used for the analysis. The usefulness of content, scale of map and time delay of map publication were assessed. The results of qualitative study are presented in tables and graphs.

\subsection{The evaluation criteria of ice data sources}

A research method of qualitative assessment adopted in this work was previously used by the author (T. Pastusiak 2015a). First, the specific characteristics of the sources that determine suitability of these sources for assessment the possibility of a vessel to overcome the ice and plot the route were determined. The scale of the relative states ranging from 0 to 1 was adopted in order to compare different sources of information (R. Kolman 1994).

Information concerning the ice cover can be transmitted by radio voice, facsimile printing on paper, on paper in form of an open text or as files in various formats: TXT, BMP, GIF, JPG, JPG2000, TIFF, PNG, EPS, GEOTIFF, NetCDF, GRIB1, GRIB, GRB, GRIB2, HDF, SIGRID-3, SHAPEFILE (SHP, SHX, DBF), KML, KMZ or GML. Some producers also compress these files in GRB.GZ, ZIP or TAR format.

Most of the ice data sources does not specify the map scale. In order to compare the accuracy of ice parameter position presented in different types of files was introduced the concept of resolution, that is, the minimum identi- 
fiable reference unit (of distance). The minimum identifiable unit of reference is in the case:

- Map of unambiguous traditional scale of maps, vector files (SIGRID-3, KML, KMZ, GML), raster graphic images and their vector transformations (BMP, JPG, PNG, GIF, TIF, EPS, PDF, etc.) - The length of the shortest section approximating the arc of isolines with the smallest observed radius;

- Gridded files (GRIB, NetCDF, HDF) - the length of the side of a single grid;

- Raster files (BMP, JPG, PNG, GIF, TIF) with a grid of averaged information that is not coincident with meridians or parallels - the length of the side of a single grid which is specified by the producer.

It was assumed that the availability of scale of considered information (table 1) and comprehensibility of map legend (table 2) facilitate the location of particular value in relation to the limit values. It also increases the precision of determining the state of an ice cover by avoiding erroneous allocation of the value.

The scale of the file type $Q_{3}$ (table 3 ) was developed taking as a criterion of quality the usefulness and simplicity of direct use in the evaluation of the possibility of overcoming sea ice and for data processing in computer software, and in mobile applications. The scale also reflects the workload for application the data source in the computerized assessment of the possibility of overcoming sea ice.

In evaluating the reliability (quality) of navigational information on nautical charts the index of "Zones of Confidence" was introduced (IHO 2014/2, T. Pastusiak 2011). It was assumed that the criterion for the reliability of the specified parameter of ice cover $Q_{4}$ will be the level of information availability on the quality parameter of ice cover. Knowledge of the quality of this parameter allows the routing decision, taking into account the reliability of ice parameter value, not just the value of a parameter (table 4).

The files are available in a certain time interval after the time for which they were issued. For example, a file containing the data for an hour of reference 00:00 today is made available to users after a few hours, a few days or even after a few weeks or months after the date and time of reference. In this work the "dilution of position $D$ " was adopted that is referring to the resolution of the map $R$, the number of hours

Table 1. Scale (legend) availability index $Q_{1}$

\begin{tabular}{|c|c|c|}
\hline No. & Description & Value of index $\boldsymbol{Q}_{\mathbf{1}}$ \\
\hline 1 & The information scale is not available in a source file & 0.0 \\
\hline 2 & $\begin{array}{c}\text { The information scale is not available in a source file. It is however available } \\
\text { in the digital part of the information (or web site) in a publication concerning } \\
\text { a given source file }\end{array}$ & 0.5 \\
\hline 3 & The information scale is available in a source file & 1.0 \\
\hline
\end{tabular}

Table 2. Comprehensibility of scale (legend) index $Q_{2}$

\begin{tabular}{|c|c|c|}
\hline No. & Description & Value of index $\mathbf{Q}_{\mathbf{2}}$ \\
\hline 1 & The scale is not clearly comprehensible or no reference & 0.000 \\
\hline 2 & Scale MIZ simplified significantly in relation to precisely defined \\
(WMO 2004/1, 2004/2) & 0.333 \\
\hline 3 & Scale SIGRID-3 (WMO 2007) simplified slightly in relation to a precisely \\
defined (WMO 2004/1, 2004/2) & 0.667 \\
\hline 4 & $\begin{array}{c}\text { The scale of information precisely defined (WMO 2004/1, 2004/2) in accepted } \\
\text { units of increments not higher as unit value }\end{array}$ & 1.000 \\
\hline
\end{tabular}


Table 3. File type index $Q_{3}$

\begin{tabular}{|c|c|c|}
\hline No. & Description & Value of index $Q_{3}$ \\
\hline 1 & $\begin{array}{c}\text { Raster graphic or other one without a grid of geographical coordinates } \\
\text { or other one not georeferenced }\end{array}$ & 0.000 \\
\hline 2 & $\begin{array}{l}\text { Text with the geographical position coordinates or positions related to the area } \\
\text { described in another document (plain text) }\end{array}$ & 0.143 \\
\hline 3 & Raster graphic with a grid of geographical coordinates & 0.286 \\
\hline 4 & Vector graphic with a grid of geographical coordinates & 0.429 \\
\hline 5 & Georeferenced raster graphic & 0.572 \\
\hline 6 & Vector or gridded georeferenced & 0.715 \\
\hline 7 & $\begin{array}{l}\text { Alphanumeric text with geographical positions as disordered / complex data } \\
\text { series }\end{array}$ & 0.858 \\
\hline 8 & $\begin{array}{l}\text { Alphanumeric text with geographical positions in this or other file } \\
\text { as a structured / simple data series }\end{array}$ & 1.000 \\
\hline
\end{tabular}

Table 4. Index of information availability on the quality of described parameter $Q_{4}$

\begin{tabular}{|c|c|c|}
\hline No. & Description & Value of index $\mathbf{Q}_{\mathbf{4}}$ \\
\hline 1 & No information about the quality of the parameter & 0.0 \\
\hline 2 & $\begin{array}{c}\text { No information about the quality of the parameter in the file containing } \\
\text { the parameter described. Information is available in a separate data source }\end{array}$ & 0.5 \\
\hline 3 & $\begin{array}{c}\text { Information on the quality of the parameter is available in the file containing } \\
\text { the parameter described }\end{array}$ & 1.0 \\
\hline
\end{tabular}

delay $A_{1}$ of maps available on the Internet in relation to the hours for which the map has been prepared and the number of hours $A_{2}$ to make the next map. Resolution and delay apply different units and there is no possibility of direct comparison of relationships between them. It was assumed that the delay $A_{1}$ and $A_{2}$ (in hours of time) will be expressed as the distance that the ice cover will be drifted during $A_{1}$ and $A_{2}$ times at a contractual uniform slight speed in relation to encountered in the Arctic in cases of extremely fast drift ice (ice jets), which threatens the safety of vessels (T. Pastusiak, A. Styszyńska 2013) and is 0.5 knot or 0.9 kilometers per hour (Equation 1).

$$
D=\sqrt[2]{R^{2}+D_{2}^{1}+D_{2}^{2}}
$$

where:

$D$ - dilution of position [km],
$R$ - resolution of the map [km],

$D_{1}$ - contractual distance which the ice will be drifting with the contractual rate of 0.926 kilometers per hour at the time $A_{1}[\mathrm{~km}]$,

$D_{2}$ - contractual distance which the ice will be drifting with the contractual rate of 0.926 kilometers per hour at the time $A_{2}[\mathrm{~km}]$.

\subsection{Total quality of data sources index}

The functions described in section 2.1 concerning the methods of assessment of the sources of information were used to calculate the indices characterizing these sources (table 5). It is assumed that the individual indices for each data source are of the same weight. On this basis, Equation 2 is obtained. It defines the value of the total quality of data sources index. It is equal the arithmetic average of all the individual 


\begin{tabular}{|c|c|c|c|c|c|c|c|c|c|c|c|c|c|c|c|c|}
\hline 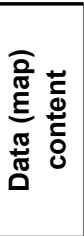 & 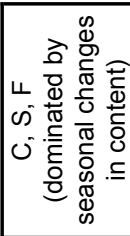 & 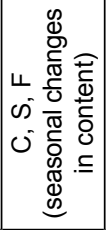 & 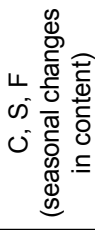 & 0 & 0 & 0 & 0 & 0 & 0 & 0 & $\begin{array}{l}4 \\
\omega^{-} \\
0\end{array}$ & $\begin{array}{l}4 \\
\text { ज } \\
0\end{array}$ & $\underset{0}{\widehat{N}}$ & $\mid \begin{array}{l}\widehat{N} \\
\sum \\
\mathcal{U}\end{array}$ & 0 & $\begin{array}{l}4 \\
\text { c } \\
0\end{array}$ \\
\hline 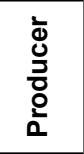 & 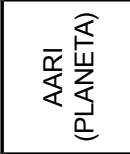 & 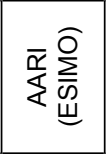 & 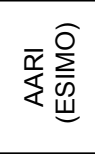 & $\frac{\bar{\alpha}}{\frac{\alpha}{\alpha}}$ & $\overline{\frac{\alpha}{4}}$ & 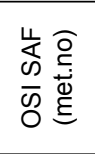 & 步 & م) & 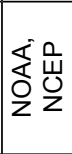 & 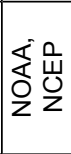 & $\frac{u}{z}$ & $\frac{U}{z}$ & $\frac{U}{Z}$ & $\frac{u}{z}$ & $\sum_{2}^{\infty} \frac{1}{1}$ & $\frac{U}{Z}$ \\
\hline 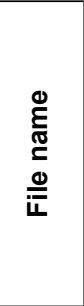 & 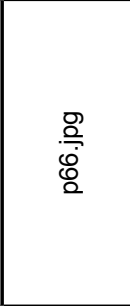 & 莺 & 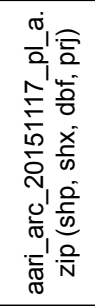 & 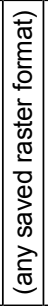 & $\begin{array}{l} \\
\vec{x} \\
\dot{0} \\
\dot{0} \\
0\end{array}$ & 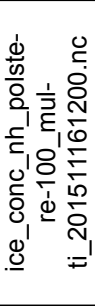 & 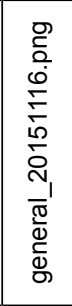 & 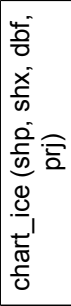 & 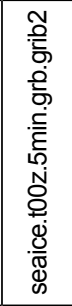 & 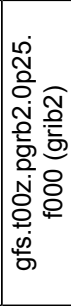 & 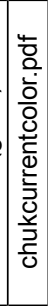 & 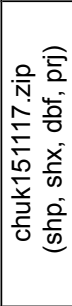 & 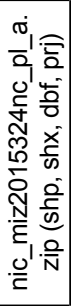 & 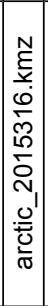 & 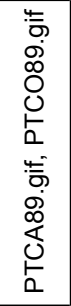 & 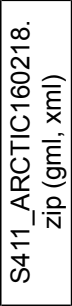 \\
\hline 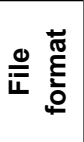 & $\begin{array}{l}0 \\
\frac{1}{7}\end{array}$ & $\frac{U}{N}$ & $\frac{0}{\frac{1}{T}}$ & $\begin{array}{l}0 \\
\vdots \\
2\end{array} \mid$ & $\stackrel{上}{x}$ & $\begin{array}{l}\text { U. } \\
0 \\
\frac{0}{2}\end{array}$ & \begin{tabular}{l}
0 \\
\hdashline
\end{tabular} & $\begin{array}{l}\frac{N}{\Sigma} \\
\text { 王 } \\
\text { 心 }\end{array}$ & $\frac{\underline{m}}{\frac{r}{0}}$ & $\frac{\underline{m}}{\frac{r}{0}}$ & 峇 & $\frac{0}{\frac{1}{T}}$ & $\begin{array}{l}\widehat{N} \\
\sum \\
\frac{0}{\Xi} \\
\text { ๘ }\end{array}$ & 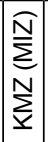 & $\frac{山}{\sigma}$ & $\sum_{0}^{\vec{O}}$ \\
\hline $\mathbf{z}$ & $r$ & - & $\nabla$ & - & 0 & $\Lambda$ & $r$ & $N$ & $\Lambda$ & $\Lambda$ & - & $\nabla$ & $\sim$ & $m$ & $r$ & ما \\
\hline$\sigma^{n}$ & $\stackrel{m}{\circ}$ & 웅 & $\begin{array}{l}\hat{0} \\
0\end{array}$ & \begin{tabular}{|l|} 
\\
$\infty$ \\
0 \\
\end{tabular} & - & $\underset{N}{\stackrel{N}{N}}$ & $\underset{N}{N}$ & $\underset{⿱ 亠 凶}{\grave{N}}$ & 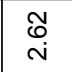 & ڤ্̀ & $\begin{array}{l}\tilde{m} \\
0 \\
0\end{array}$ & $\stackrel{m}{0}$ & $\stackrel{\forall}{\forall}$ & $\underset{\sim}{\stackrel{*}{*}}$ & $\begin{array}{l}\hat{\omega} \\
\infty \\
\dot{n}\end{array}$ & $\stackrel{m}{0}$ \\
\hline 口 $\underset{\underline{\underline{\xi}}}{\overline{\underline{g}}}$ & $\stackrel{\infty}{m}$ & 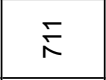 & $\mp$ & in & ల్ & $\stackrel{\mathscr{N}}{ }$ & N & N & $\stackrel{N}{\sim}$ & $\stackrel{\mathbb{N}}{ }$ & $\stackrel{\sim}{n}$ & is & $\hat{N}$ & $\hat{N}$ & N & 占 \\
\hline 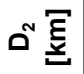 & 命 & $\begin{array}{l}\infty \\
: \\
0\end{array}$ & $\begin{array}{l}\infty \\
: \\
0\end{array}$ & $m$ & N & 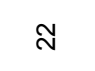 & N & N & N & 0 & 占 & 号 & N & N & N & $\stackrel{L}{\stackrel{L}{\circ}}$ \\
\hline$\Phi^{-\frac{\vec{E}}{\underline{\xi}}}$ & $\mathbb{N}$ & $\stackrel{\infty}{\stackrel{2}{\leftarrow}}$ & $\stackrel{\infty}{\simeq}$ & $\cong$ & $\stackrel{9}{\square}$ & (م) & $m$ & $m$ & $F$ & $\nabla$ & $\approx$ & $\approx$ & $\stackrel{\bullet}{ }$ & $\stackrel{20}{2}$ & $\nabla$ & $\mp$ \\
\hline \&旁 & $\stackrel{\infty}{\circ}$ & 导 & 导 & $\infty$ & $\stackrel{\Delta}{\sim}$ & $\stackrel{\nabla}{\sim}$ & $\stackrel{ম}{N}$ & $\stackrel{\mathbb{N}}{ }$ & $\stackrel{\mathbb{N}}{ }$ & 0 & $\stackrel{\infty}{\varrho}$ & $\stackrel{\infty}{\varrho}$ & $\stackrel{\Xi}{\sim}$ & $\stackrel{ \pm}{\sim}$ & $\stackrel{ম}{N}$ & $\stackrel{\infty}{\varrho}$ \\
\hline <党 & $\stackrel{ \pm}{\sim}$ & ๙ & $\widetilde{\Omega}$ & $\stackrel{m}{-}$ & $\bar{N}$ & ما & $m$ & $m$ & $\stackrel{N}{\sim}$ & $\nabla$ & $\stackrel{d}{\Delta}$ & $\stackrel{d}{N}$ & 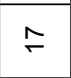 & 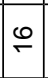 & $\nabla$ & $\stackrel{N}{\sim}$ \\
\hline$\propto \underset{\underline{\underline{E}}}{\overrightarrow{\underline{g}}}$ & مْ & 아 & $\stackrel{\infty}{\circ}$ & 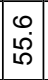 & 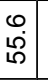 & 웅 & $\stackrel{\cong}{\sigma}$ & $\stackrel{\circ}{\circ}$ & $\stackrel{m}{\sigma}$ & $\stackrel{\infty}{\stackrel{N}{N}}$ & $\stackrel{9}{\text { m. }}$ & $\stackrel{\text { N }}{0}$ & $\stackrel{\circ}{-}$ & $\stackrel{\circ}{\circ}$ & $\stackrel{\infty}{m}$ & ָ̃ \\
\hline$\sigma^{\infty}$ & $\begin{array}{l}\qquad 0 \\
0 \\
0\end{array}$ & $\begin{array}{l}\overbrace{0} \\
0 \\
0\end{array}$ & $\stackrel{\mathscr{0}}{0}$ & \begin{tabular}{|l|} 
\\
0 \\
0 \\
0
\end{tabular} & $\begin{array}{l}m \\
\infty \\
0 \\
0\end{array}$ & б. & $\begin{array}{l}0 \\
\stackrel{1}{0} \\
0\end{array}$ & $\begin{array}{l}\mathscr{C} \\
0\end{array}$ & б. & б. & $\hat{0}$ & $\begin{array}{l}\ddot{0} \\
0\end{array}$ & $\begin{array}{l}\text { กิ } \\
0 \\
0\end{array}$ & 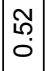 & $\begin{array}{l}\stackrel{0}{0} \\
0\end{array}$ & $\begin{array}{l}\mathscr{6} \\
\ddot{0}\end{array}$ \\
\hline 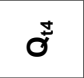 & ণ্? & ণ্ণ & f & $\begin{array}{l} \\
\\
\\
\end{array}$ & $\begin{array}{l}m \\
0 \\
0\end{array}$ & $\begin{array}{l}\mathscr{O} \\
\text { O }\end{array}$ & 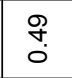 & 守 & $\begin{array}{l}\infty \\
\stackrel{0}{0} \\
0\end{array}$ & \begin{tabular}{l}
$\infty$ \\
\hdashline \\
0
\end{tabular} & $\begin{array}{l}\tilde{N} \\
\tilde{0} \\
0\end{array}$ & f̊ & 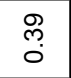 & 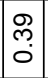 & $\begin{array}{c}N \\
\infty \\
0 \\
0\end{array}$ & f̊ \\
\hline ठ & 0 & 0 & $c$ & 0 & 0 & - & 0 & 0 & 0 & 0 & 0 & 0 & 0 & 0 & - & 0 \\
\hline$\sigma^{\infty}$ & $\begin{array}{l}\stackrel{0}{0} \\
\stackrel{0}{N} \\
0\end{array}$ & $\begin{array}{l}0 \\
\stackrel{0}{0} \\
\stackrel{2}{0}\end{array}$ & $\begin{array}{l}\frac{10}{5} \\
0 \\
0\end{array}$ & 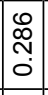 & - & $\begin{array}{l}\frac{10}{\pi} \\
0 \\
0\end{array}$ & $\begin{array}{l}\stackrel{0}{0} \\
\stackrel{0}{N} \\
0\end{array}$ & $\begin{array}{l}\frac{10}{5} \\
0\end{array}$ & $\begin{array}{l}\frac{n}{\pi} \\
0 \\
0\end{array}$ & $\begin{array}{l}\frac{10}{5} \\
0\end{array}$ & \begin{tabular}{l}
\multirow{2}{*}{} \\
\multirow{0}{*}{} \\
\end{tabular} & $\begin{array}{l}\frac{10}{5} \\
0 \\
0\end{array}$ & $\begin{array}{l}\stackrel{n}{\Lambda} \\
0 \\
0\end{array}$ & 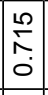 & $\begin{array}{l}\stackrel{0}{0} \\
\stackrel{0}{N} \\
0\end{array}$ & $\begin{array}{l}\frac{n}{\pi} \\
0 \\
0\end{array}$ \\
\hline ชే & $\begin{array}{l}\hat{\theta} \\
0 \\
0\end{array}$ & $\begin{array}{l}\hat{0} \\
\varnothing \\
0\end{array}$ & $\begin{array}{l}\hat{\&} \\
0 \\
0\end{array}$ & \begin{tabular}{|l|}
$\hat{0}$ \\
0 \\
0
\end{tabular} & - & $r$ & $\begin{array}{l}\hat{\emptyset} \\
0 \\
0\end{array}$ & $\begin{array}{l}\hat{\emptyset} \\
0 \\
0\end{array}$ & $r$ & $r$ & $\begin{array}{l}\hat{0} \\
\stackrel{0}{0} \\
\dot{0}\end{array}$ & $\begin{array}{l}\hat{0} \\
\vdots \\
0\end{array}$ & $\underset{m}{\tilde{O}}$ & \begin{tabular}{|c}
$\mid$ \\
$\tilde{m}$ \\
0 \\
0
\end{tabular} & - & $\begin{array}{l}\hat{\emptyset} \\
\vdots \\
0\end{array}$ \\
\hline ơ & $r$ & $r$ & مُ & - & $\begin{array}{l}0 \\
0 \\
0\end{array}$ & $r$ & - & مْ & - & - & - & مْ & مْ & $\mid \begin{array}{l}10 \\
0 \\
0\end{array}$ & - & مִ \\
\hline i & $r$ & $N$ & $m$ & $\nabla$ & م & 0 & N & $\infty$ & a & 음 & $\mp$ & $\stackrel{\sim}{\sim}$ & $\stackrel{m}{\square}$ & 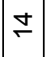 & $\stackrel{\circ}{\sim}$ & $\stackrel{\bullet}{ }$ \\
\hline
\end{tabular}


indices $Q_{t 4}$. Thus obtained total quality of data sources index allows comparison of the quality of different sources of information. It should be noted that the index characterizes only the simplicity of use of the content of the information contained in the data source file.

$$
Q_{t 4}=\frac{Q_{1}+Q_{2}+Q_{3}+Q_{4}}{4}
$$

where:

$Q_{t}-$ total quality of data sources index,

$Q_{1}$ - scale (legend) availability index,

$Q_{2}$ - comprehensibility of scale (legend) index,

$Q_{3}-$ file type index,

$Q_{4}$ - index of information availability on the quality of described parameter.

Due to the small number of sources with information on the quality of the presented parameter also used index $Q_{t 3}$ for the three partial indexes in the analysis $Q_{1}, Q_{2}$ and $Q_{3}$. Equation 1 concerns the parameters of geographical space, and the Equation 2 concerns the usable quality of ice map. In order to link both formulas (that are qualitative) by a formula reflecting the size of a measurable geographic space the equation 3 was adopted, which synthesizes both indexes:

$$
Q_{s}=\frac{100 \cdot Q_{t}}{D}
$$

where:

$Q_{s}$ - synthetic data source (map) quality index [km],

$Q_{t 3}$ - total quality of data sources index for $Q_{1}$, $Q_{2}$ and $Q_{3}$,

$D$ - dilution of position [km].

It should be emphasized that the indices and indexes developed by the author and presented in the work are innovative solution. They allow to analyze not considered so far a new problem. For similar reasons, J.P. Girjatowicz $(1983,1985)$ has developed index of winters severity.

\section{Characteristics of analyzed data sources}

There are many online public sources of information about the state of the ice cover. The files, which reports the WMO or IHO for use in navigation (WMO 2000, 2005, 2010/1, 2010/2;
IHO 2014/1) were selected. Also were used files that well characterize a given group of data sources and at the same time have the best resolution. A significant number of data sources has been extensively described in the earlier work of T. Pastusiak (2015b). Most of the sources analyzed in this article is disseminated in the GMDSS system or on the JCOMM website. Summary of theirs characterictics is placed in table 5. There are:

1. Maps of concentration of ice, age and form of ice, and many other detailed information for the selected regions of the Arctic Ocean in raster JPG format (http://www.bsis-ice.de/lcePortal/Metareas.html, accessed 22.02.2016). Maps are developed thematically appropriate to the needs of recipients of the information.

2. Maps of concentration or age of ice in the Arctic Ocean in raster GIF format (http://www. aari.ru/projects/ecimo/index. php? im=100, accessed 22.02.2016). In the summer season the maps contain an analysis of ice concentration and in the winter season contain analysis of the ice age. Maps are compiled on the basis of the analysis of satellite information (in the visible, infrared and radar bands), and reports from shore stations and vessels. Data are collected in the period of 2-5 days and after averaging issued every Thursday.

3. Maps of concentration, age and form of ice on the Arctic Ocean in vector ESRI Shapefile format (http://www.aari.ru/projects/ecimo/index. php?im=100, accessed 22.02.2016). In the summer season include an analysis of concentration, age and form of ice. At that time information about the concentration of ice are always described and information on the form of ice are often presented. Conversely, information about ice age are presented sporadically. In the winter season the maps contain the analysis of an ice age.

4. Maps of computational prediction of ice concentration in the Arctic Ocean in the form of isolines in raster format (http://ocean8x.aari. nw.ru/index.php?id=600\&model=3, accessed 22.02.2016). Maps are compiled on the basis of the calculation model of the process of dynamics of the total mass of water and ice. The forecast covers 00 to 144 hours in increments of three hours from the date and time of reference.

5. Maps of computational predictions of many hydrological and meteorological parameters in the Arctic Ocean in text alphanumeric TXT 
format. (http://www.aari.ru/projects/ecimo/, accessed 22.02.2016). The ice concentration, compacting, wind and sea current speed and direction, and drift of ice are described. Maps are compiled on the basis of the calculation model of the process of dynamics of the total mass of water and ice. The forecast includes from 1 to 6 days from the date and time of reference with increments of one day time.

6. Maps of ice concentration in the Arctic Ocean in a grid NetCDF format (ftp://osisaf.met. no/archive/ice/conc, accessed 22.02.2016). The scale of ice concentration on the exported raster file (using HDF Explorer software) is not clear for understanding. The raster image missing lines of geographical coordinates. It is possible to read the geographical position and other parameters of ice cover in the HDF Explorer software or from exported data series from NetCDF file to a simple file format TXT, CSV, XLSX or to complex construction data file TXT, PRN, CSV, XLSX.

7. Maps of ice floe concentration in the European part of the Arctic Ocean in raster JPG format with a grid of geographical coordinates (ftp://ftp.dnmi.no/projects/icecharts, accessed 22.02.2016). Sources of the original

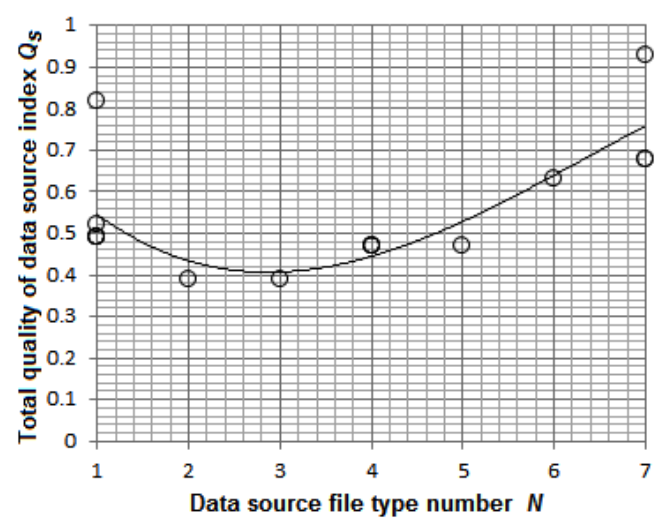

Fig. 1. Total quality index $Q_{t}$ values for the successive groups of data sources $N$ : 1 - raster graphic files, 2 - vector files ESRI Shape type with simplified scale of data (MIZ), 3 - vector files KMZ type with simplified scale of data (MIZ), 4 - vector ESRI Shape type file with extended scale of data (SIGRID-3), 5 - vector GML type files according to S-411 standard, 6 - text files with ordered data series, 7 - gridded GRIB and NetCDF type files information are high-resolution maps up to 75-150 meters. Thanks to this they allow one to specify the ice conditions in the fjords and straits of width of even just a few kilometers.

8. Maps of ice floe concentration in the European part of the Arctic Ocean in vector ESRI Shapefile format (ftp://ftp.dnmi.no/projects/icecharts, accessed 22.02.2016). Notes are the same as in the previous data sources.

9. Maps of ice floe concentration in the Arctic Ocean in gridded GRIB format (http://nomads. ncep.noaa.gov/pub/data/nccf/com/omb/prod/, accessed 22.02.2016). No information about the original sources from which they were made. Map grid resolution is 5 minutes latitude by $5 \mathrm{mi}-$ nutes longitude.

10. Maps of Maps of analysis and forecasts of ice concentration from 00 to 384 hours in the Arctic Ocean in GRIB2 format. They contain information on many hydrological and meteorological parameters (ftp://ftpprd.ncep.noaa.gov/pub/ data/nccf/com/gfs/prod/, accessed 22.02.2016). No information about the original sources from which they were made. Map grid resolution is 0.25 degrees latitude by 0.25 degrees longitude.

11. Maps of ice concentration, ice age and form of ice for selected regions of the Arctic Ocean with grid coordinates in vector PDF format (http://www.bsis-ice.de/lcePortal/Metareas.html, accessed 22.02.2016). The grid of geographic coordinates in the polar stereographic projection is not shown accurately. White color parallels and meridians are not visible on a white background of maps free of information and makes difficult to read the exact position of the ice parameter.

12. Maps of the analysis of ice concentration, ice age and form of ice for selected regions of the Arctic Ocean in vector ESRI Shape format (http://www.natice.noaa.gov/products/weekly_ products.html, accessed 22.02.2016).

13. Maps of ice concentration in a simplified scale of Marginal Ice Zone in the Arctic Ocean in vector ESRI Shape format (http://www.natice. noaa.gov/products/daily_products.html, accessed 22.02.2016). Maps are compiled from various sources with a resolution of better than 50 meters per pixel. The NIC analysts carry out the necessary, correct interpretation of these data sources for proper identification of the extent of the ice limits. The NIC's mission is to deliver the highest quality of regular, accurate products and services related to the USA stra- 
tegic, operational and tactical needs compliant with the scope of the area of responsibility.

14. Maps of ice concentration in a simplified scale of Marginal Ice Zone in the Arctic Ocean in vector KMZ format (http://www.natice.noaa.gov/ products/kml_daily.html, accessed 22.02.2016). Notes are the same as in the previous data sources.

15. Facsimile maps disseminated by GMDSS system of analysis and 120-hour forecasts of ice concentration and thickness in the area of the Chukchi Sea and the Bering Strait in GIF format with geographic coordinates grid (http:// weather.noaa.gov/pub/fax/PTCA89.gif and http://weather.noaa.gov/pub/fax/PTCO89.gif, accessed 22.02.2016).

16. Maps of the analysis of ice floe concentration, ice thickness and size of ice floe for selected regions in the vector GML format (http:// www.bsis-ice.de/lcePortal/ILP S411.shtml, accessed 22.02.2016). No information about the original sources from which they were made.

Then the above-mentioned characteristics of data sources were analyzed. Taken into account their inter-dependence.

\section{Evaluation of selected data sources}

Analysis of partial quality indexes that make up the total quality index $Q_{t}$ (table 5 ) showed that indexes $Q_{1}$ and $Q_{2}$ have a tendency inversely proportional to the index $Q_{3}$. Only for text TXT files with ordered data series and for gridded GRIB and NetCDF files these three indexes have a consistent trend. This resulted in a higher value of the total quality index $Q_{t}$ for these two groups of files.

About half of the data sources are characterized by a low dilution of geographical position $D$ of ice parameter. The term "dilution of position $D$ " is understood as the sum of the data source resolution $R$ and the contractual drift of ice cover $D_{1}$ and $D_{2}$. It includes the data source over the entire range of the total quality $Q_{t}$. Only some sources have a high value of dilution $D$. They are characterized by poor values of total quality index $Q_{t}$.

Only some sources from the group 1 (raster graphic files) and 7 (grid type NetCDF files) have information on the reliability of the presented parameter of ice cover (fig. 1). This resulted in a considerable large range of total quality index $Q_{t}$ within these groups. If omitted the reliability impact on the total quality index of data source, the trend curve shows similar performance for most sources of information within groups from 1 to 5 . Slightly reduced value of total quality index $Q_{t}$ have vector ESRI Shape type and vector $K M Z$ type files with a simplified range of scale (MIZ). Noticeably higher quality are text TXT files with the ordered data series and gridded GRIB and NetCDF type files.

Most sources is characterized by a resolution $R$ of less than one kilometer (fig. 2). Few sources have the resolution of value between 1 and $10 \mathrm{~km}$. Only two of the studied data sources have the resolution of 5-10 times higher (worse). A much greater impact on the dilution of position $D$ has contractual ice drift resulting from the delay to provide recipients the data source. The lowest values begin with 10 kilometers. A significant number of sources is characterized by value of the contractual ice drift $D$ above $30 \mathrm{~km}$. It is assumed that the data sources characterized by the value of contractual ice drift above $100 \mathrm{~km}$ are practically useless for the purposes of voyage planning in ice for the currently undertaken navigation. For imagination the above dependences, the voyage time of the vessel, which corresponds to dilution of position $(10,30,100 \mathrm{~km})$ for the speed of $20 \mathrm{~km} / \mathrm{h}$ was calculated. So the calculated voyage time of the vessel is, respectively, 0.5 hours, 1.5 hours and 5 hours.

Dilution of position $D$ that is taking into account the resolution $R$, contractual distance $D_{1}$ associated with the delay $A_{1}$ of sharing the file on the Internet and the contractual distance $D_{2}$ related with the delay $A_{2}$ of sharing the next file is usually between values of 10 and 100 kilometers (fig. 3). There are data sources among the raster type files and vector ESRI Shape type files with an extended range of data according to the standard SIGRID-3, which far exceed dilution of position $D$ value of $100 \mathrm{~km}$. They have no utility value for value for vessel's voyage planning in ice. Excluding text TXT files containing a number of ordered data series, in other groups can be selected files with the dilution of position $D$ in the range of 10 to $53 \mathrm{~km}$.

The best source of these analyzes will be a source that have the least value of dilution of position $D$ and the highest value of the total quality index $Q_{t 3}$. It is expected that a synthetic quality indicator of data sources $Q_{S}$ should also have the highest values. These indices are 


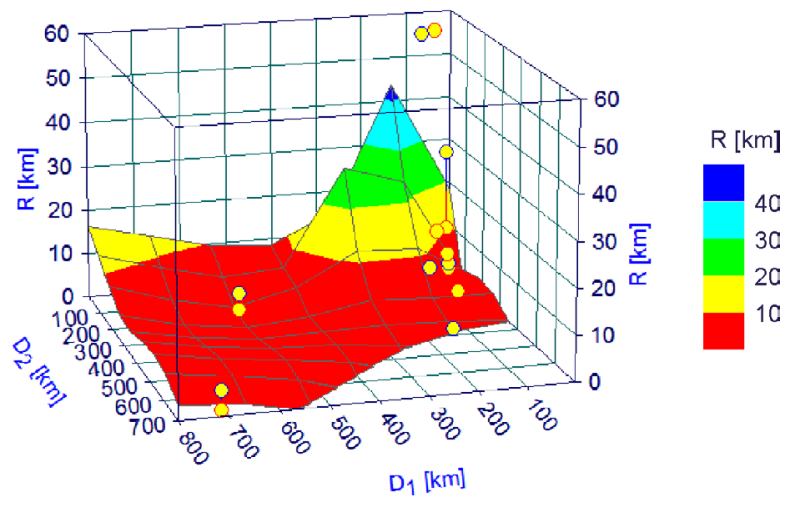

Fig. 2. Inter-dependence of the contractual ice drift $D_{1}$ and $D_{2}$, and the resolution of the ice data sources $R$

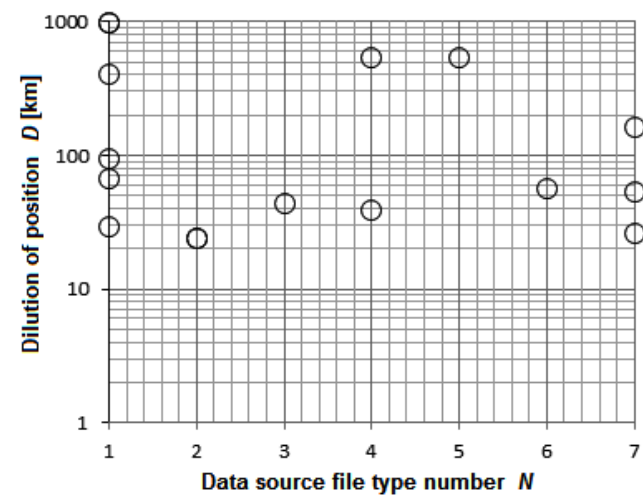

Fig. 3. Value of dilution of position $D$ for the successive groups of data sources $N$ : 1 - raster graphic files, 2 - vector files ESRI Shape type with simplified scale of data (MIZ), 3 - vector files KMZ type with simplified scale of data (MIZ), 4 - vector ESRI Shape type file with extended scale of data (SIGRID-3), 5 - vector GML type files according to S-411 standard, 6 - text files with ordered data series, 7 - gridded GRIB and NetCDF type files

shown in the single graph (fig. 4). In the first place rated all sources of information. The best sources turned out to be regional maps No. 15 in GIF format issued by the NWS / NOAA (fig. 5), and then general map of the Arctic No. 6 in the NetCDF format issued by OSI SAF (fig. 6) and general maps of the Arctic Ocean No. 10 in the GRIB-2 format issued by the NCEP / NOAA (fig. 7). Two of these maps (No. 15 and 6) contain information about the quality of the pre-

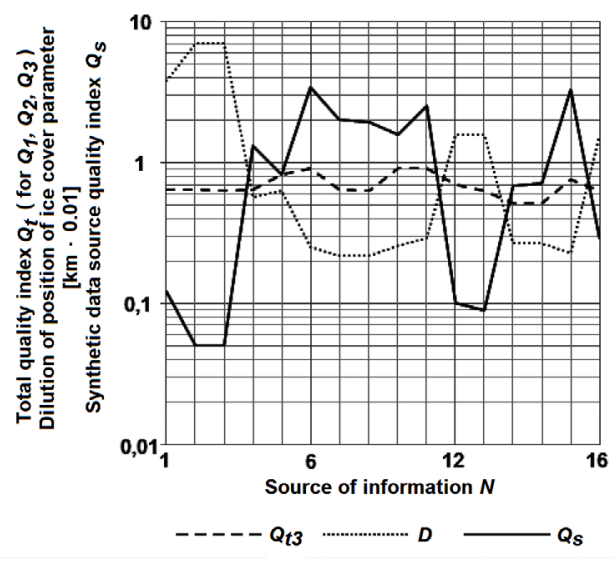

Fig. 4. Complex indicators $Q_{t 3}, D$ and $Q_{s}$ of data sources with numbers from 1 till 16

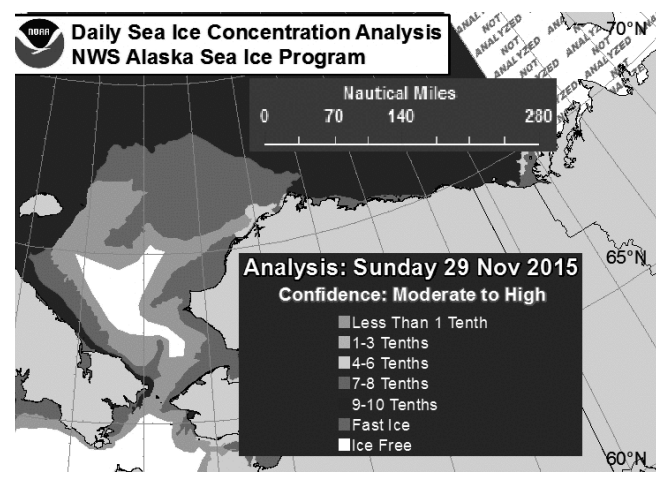

Fig. 5. Regional map in polar stereographic projection No. 15 in GIF format issued by the NWS / NOAA 
sented ice parameter. They occupied a high position, even though this parameter was not here evaluated. Next, there are regional maps No. 7 in JPG format and maps No. 8 in ESRI Shape format issued by the NIS, general map of the Arctic Ocean No. 9 in a GRIB format and No. 10 in a GRIB-2 format issued by the NCEP I NOAA and raster maps No. 4 issued by AARI of many parameters of ice cover for the Arctic Ocean.

Next, rated maps of content covering the full range of information (ice concentration, ice age and horizontal size of ice floes) and represented by small numbers of data sources No. 1, 2, 3, 11, 12 and 16. Sources No. 2, 3, 11 and 12

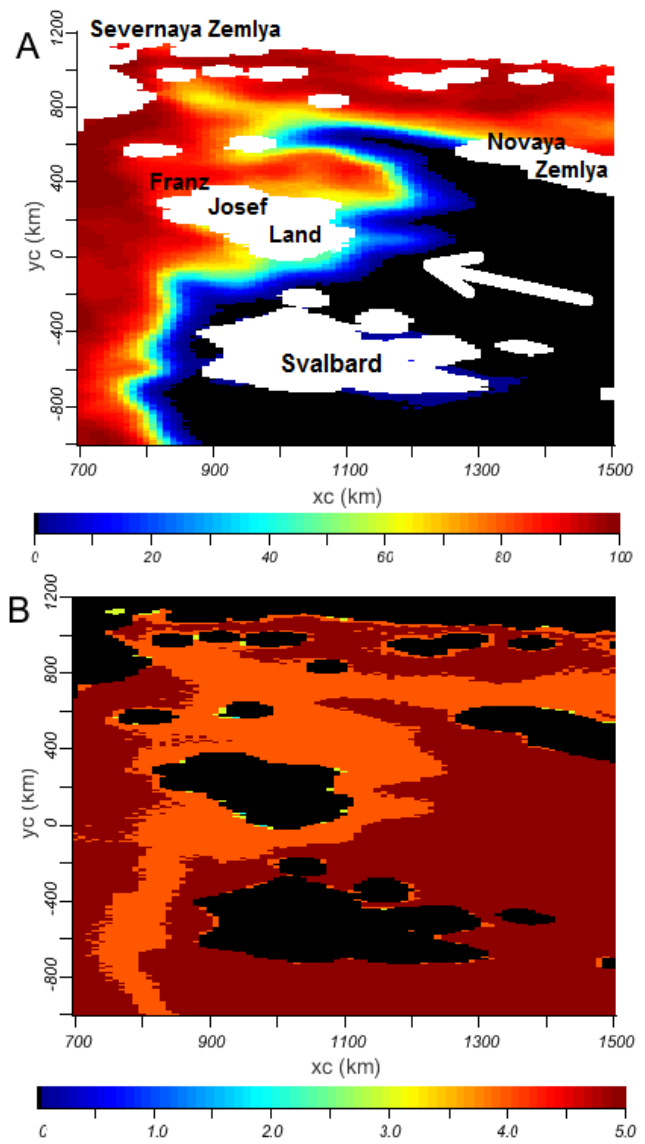

Fig. 6. General map of the Arctic Ocean in the polar stereographic projection No. 6 in NetCDF format issued by OSI SAF: A - ice concentration, B - reliability parameter (Visualization software: ncBrowse) were rejected because of the very high values of dilution of position $D$ (fig. 6). In this situation, the leaders have been general maps of the Arctic Ocean No. 16 in GML format issued by the NIC (fig. 8) and regional maps for the Russian Arctic in JPG No. 1 with a significantly lower value of the synthetic quality index $Q_{s}$ issued by AARI.

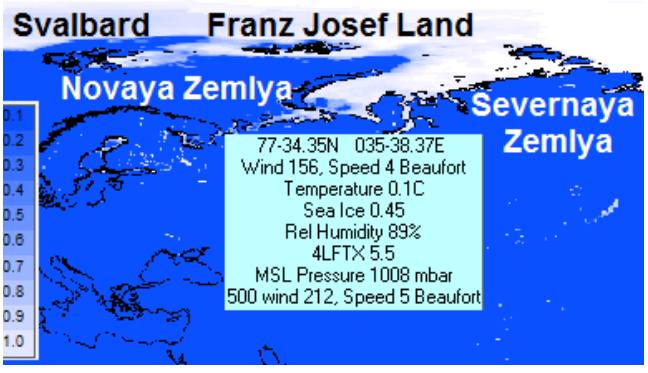

Fig. 7. General map of the Arctic Ocean in a geographical system No. 10 in GRIB-2 format issued by the NCEP / NOAA (Visualization software: BallGate GRIB Weather File Viewer Professional)

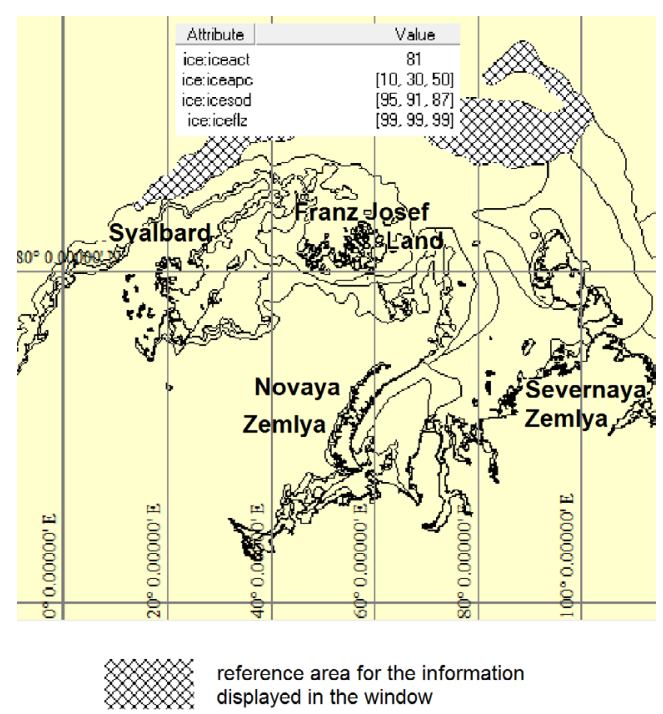

Fig. 8. General map of the Arctic Ocean of S-411 standard in the Mercator projection No. 16 in GML format issued by NIC (Visualization software: Global Mapper) 


\section{Conclusions}

In the research process the synthetic data sources quality index binding all quality indices was developed. It reflects well usable quality of maps and allows them to make comparisons. Among all examined sources the highest value of the synthetic quality index gained regional maps in GIF format issued by the NWS I NOAA, general maps of the Arctic Ocean in NetCDF format issued by OSI SAF and general maps of the Arctic Ocean in GRIB-2 format issued by the NCEP / NOAA. The highest positions in this group achieve maps, which producers supply them with information about the quality of the presented parameter. High position also receive maps in gridded GRIB and NetCDF format. The number of maps containing all three basic characteristics of the ice cover (ice concentration, ice thickness and horizontal size of ice floe) is low. The best source in this group turned out to be vector maps in GML format, which is the new standard of electronic vector maps for navigation of vessels in ice. It is the format and service for GIS data exchange for description of spatial information. Enables the use of open source software and data downloads from the external servers. At the moment,

\section{List of acronyms}

AARI - Arctic and Antarctic Research Institute BSH - Bundesamt für Seeschiffahrt und Hydrographie

DGPS - Differential Global Positioning System

ECDIS - Electronic Chart Display and Information System

ECS - Electronic Chart System

ENC - Electronic Navigational Charts

ESIMO - ЕСИМO, Единая Система Информации об обстановке в Мировом Океане

GMDSS - Global Maritime Distress and Safety System GPS - Global Positioning System

HDOP - Horizontal Dilution of Precision

IENC - Inland Electronic Navigational Charts

$\mathrm{IHO}$ - International Hydrographic Office not all commercial computer software allow it. Maritime electronic chart display and information systems ECDIS else do not support S-411 standard in GML format as another information layer.

Quality differences of maps content seem to have less impact on the overall assessment of the data sources than arises from uncertainty of the position of the described parameter. Resolution of maps is acceptable in most cases. The greatest impact on the map quality content (synthetic quality index) for the currently planned voyage in ice has its actuality. The delay in providing maps to the users in relation to the reference date and time as well as the time interval between successive releases of maps is the most important for the usable quality of information. These delays can make maps even useless for current needs of navigation in ice.

The time delay of sharing information about ice cover for the purposes of navigation on the lagoons and bays at sea as well as on lakes and inland waterways, including rivers and canals in Poland and in Europe should not be greater than 24 hours. Maps with the highest value of the synthetic quality index for the region of the Arctic Ocean are published mostly in these intervals.
JCOMM - Joint Technical Commission for Oceanography and Marine Meteorology

MIZ - Mariginal Ice Zone

NCEP - National Centers for Environmental Prediction

NIC - US National Ice Center

NIS - National Ice Service

NOAA - National Oceanic and Atmospheric Administration

NWS - National Weather Service

OSI SAF - Ocean and Sea Ice Satellite Application Facility

RNC - Raster Navigational charts

SOLAS - International Convention for the Safety of Life at Sea

WMO - World Meteorological Organization 


\section{References}

Girjatowicz J.P., 1983, Stopień surowości zim i możliwość jego przewidywania na podstawie niektórych zjawisk fenologiczno-przyrodniczych [in Polish]. „Zeszyty Naukowe Akademii Rolniczej w Szczecinie" Nr 103, pp. 65-73.

Girjatowicz J.P., 1985, Atlas zlodzenia wód polskiego wybrzeża Bałtyku [in Polish]. Szczecin: Akademia Rolnicza w Szczecinie, 27 pp.

IHO, 2000/1, IHO Transfer Standard for Digital Hydrographic Data, S-57. Monaco, 435 pp.

IHO, 2000/2, S-57 Appendix A, IHO Object Catalogue. Monaco, 248 pp.

IHO, 2012, Symbols, abbreviations and terms used on charts, INT 1 (French version). 2012, 132 pp.

IHO, 2013, Regulations for International (INT) Charts and Chart Specifications of the IHO, S-4. 435 pp.

IHO, 2014/1, Ice Information Product Specification, JCOMM S-411. Monaco, 47 pp.

IHO, 2014/2, Transfer Standard for Digital Hydrographic Data, S-57, Supplementary information for the encoding of S-57, Monaco, 24 pp.

Kolman R., 1994, Poradnik dla doktorantów i habilitantów [in Polish]. Bydgoszcz: Oficyna Wydawnicza Ośrodka Postępu Organizacyjnego, 295 pp.

Malicki J., Turchin A.N., Valeur H.H., 1987, Baltic multilingual list of sea-ice terms, Marine meteorology and related oceanographic activities. Report No. 18, WMO/TD No. 160, World Meteorological Organization.

Pastusiak T., 2011, Ship's Navigational Safety in the Arctic Unsurveyed Regions. In: Maritime Navigation and Safety at Sea Transportation. Miscellaneous problems in maritime navigation, transport and shipping. A. Weintrit, T. Neumann (eds.), London: CRC Press Taylor \& Francis Group, pp. 59-64.

Pastusiak T., 2015a, Navigation infrastructure of the Northern Sea Route. "Scientific Journals of the
Maritime University of Szczecin” Nr 44 (116), Szczecin, pp. 74-82.

Pastusiak T., 2015b, Ship's Route Planning in Ice Infested. Areas of Northem Svalbard Following Ice Charts Made by Remote Sensing Methods. In: Maritime Navigation and Safety at Sea Transportation. Miscellaneous problems in maritime navigation, transport and shipping. A. Weintrit (ed.), London: CRC Press, pp. 181-192.

Pastusiak T., Styszyńska A., 2013, Intensywny dryf lodu $w$ rejonie wyspy Wrangla, zjawiska z nim związane i konsekwencje dla bezpieczeństwa żeglugi [in Polish]. „Problemy Klimatologii Polarnej” Nr 23, Gdynia, pp. 191-204.

Weintrit A., 2009, The Electronic Chart Display and Information System (ECDIS), An Operational Handbook. CRC Press/Balkema, $1101 \mathrm{pp}$.

WMO, 2000, Sea-Ice Information Services in the World. Edition 2000, WMO No. 574, Geneva, 75 pp.

WMO, 2004a. WMO Colour Code Standards. WMO/ TD No. 1215, JCOMM Technical Report No. 24, $14 \mathrm{pp}$.

WMO, 2004b, WMO Sea-Ice Nomenclature Terminology. WMO/OMM/BMO No. 259, Vol. 1, Edition 1970-2004, 7 pp.

WMO, 2005, Sea-Ice Information Services in the World. Edition 2005, WMO No. 574: 100 pp.

WMO, 2007, SIGRID-3: A Vector Archive Format for Sea-lce Charts. WMO/TD No. 1214, 2004 (with revisions by ETSI-III, March 2007), JCOMM Technical Report No. 23.

WMO, 2010/1, Manual on Codes, International Codes. Vol. I (Annex II to WMO Technical Regulations), Part A - Alphanumeric Codes, WMO No. 306, 462 pp.

WMO, 2010/2, Sea-lce Information Services in the World. Edition 2010, WMO No. 574, Geneva, $92 \mathrm{pp}$. 